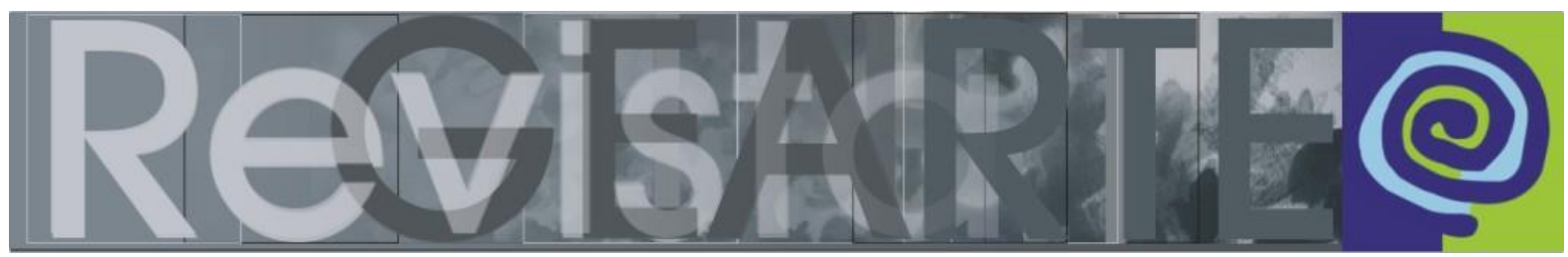

e-ISSN 2357-9854

\title{
Observatório da formação de professores de Artes Visuais: uma análise à luz das políticas vigentes
}

\author{
Maria Cristina da Rosa Fonseca da Silva (Universidade do Estado \\ de Santa Catarina — UDESC, Florianópolis/SC, Brasil) \\ Valéria Metroski de Alvarenga (Secretaria do Estado da Educação \\ do Paraná - SEED, Maringá/PR, Brasil) \\ Claudia Carnevskis Bellan (Universidade Federal do Amazonas - \\ UFAM - Campus Parintins/AM, Brasil)
}

\begin{abstract}
RESUMO - Observatório da formação de professores de Artes Visuais: uma análise à luz das políticas vigentes - Apresenta-se o Observatório da Formação de Professores no âmbito do Ensino de Artes: estudos comparados entre Brasil e Argentina, com destaque à coleta de dados na Região Norte em comparação à Região Sul do Brasil. O estudo, à luz das políticas públicas vigentes e dos processos de expansão universitária, analisa pontos de intersecção entre as licenciaturas em Artes Visuais. Em função de políticas públicas neoliberais, implantadas a partir de 1990 na América Latina, há pouco espaço para aspectos culturais regionais, fortalecendo-se, desse modo, as relações de uniformização da atuação docente, precarização do professor e paulatina perda de seu papel como intelectual transformador. Conclui-se que as duas regiões formam professores de Artes Visuais de modo muito semelhante, que a prática social específica é minimizada e que o tema dos conteúdos, historicamente acumulados, é precariamente abordado. Destaca-se, finalmente, que essa homogeneização é fruto da legislação vigente.
\end{abstract}

PALAVRAS-CHAVE

Artes Visuais. Formação docente. Observatório.

ABSTRACT - Observatory of teacher training of visual arts: an analysis in the light of current policies - Here is presented the Observatory of Teachers Training in the area of Arts Teaching: comparing case studies in Brazil and Argentina, focusing on data collected in the North region of Brazil, as compared to the South region. The case study, in the light of current policies and college expansion processes, analyzes intersection points in Visual Arts teaching courses. Due to neoliberal public policies, established since 1990 in Latin America, there is little space for regional cultural aspects, thus strengthening relationships of uniforming educators' performance, hampening teachers, and steady loss of their role as intellectual transformers. As a conclusion, both regions train Visual Arts teachers in a very similar way, specific social practice is minimized, and the syllabus themes, historically stacked, are barely brought up. Finally, it should be noted that this homogenization is a consequence of the current laws.

\section{KEYWORDS}

Visual Arts. Teacher training. Observatory. 


\section{Introdução}

Apresentam-se neste artigo estudos desenvolvidos pelo projeto em rede Observatório da Formação de Professores no Âmbito do Ensino de Artes: estudos comparados entre Brasil e Argentina, em especial pelo grupo de pesquisa da Udesc. O projeto, gestado em 2011, conquistou aporte financeiro do Mincyt ${ }^{1}$ e da Capes $^{2}$, desenvolvendo suas atividades entre 2012 e 2014.

Após três anos, a configuração do observatório ampliou-se, constituindo-se um grupo com mais de $12^{3}$ universidades e três institutos federais ${ }^{4}$. Este recorte apresenta estudos desenvolvidos na Udesc, considerando-se as pesquisas introdutórias de Hillesheim (2013), Azevedo (2014), Schlichta (2015), Fonseca da Silva, Sosnowski e Mazurkievicz (2013), e Fonseca da Silva, Hillesheim e Makoviecky (2013).

$\mathrm{Na}$ segunda etapa deste artigo, apresentam-se os estudos focados nos seguintes estados e Regiões: (1) Santa Catarina - Collaço, Jensen e Fonseca da Silva (2016); Fonseca da Silva, Azevedo, Pera e Alvarenga (2014); Pera e Fonseca da Silva (2014); Fonseca da Silva (2017); (2) Paraná - Alvarenga (2015); Schlichta e Alvarenga (2015); (3) Rio Grande do Sul - Muller (2017); e (4) Região Nordeste - Silva Santos (2017); e ainda uma tese em desenvolvimento, de Janine Alexandra Perini, com previsão de término em 2020. Da Região Norte, apresentam-se duas pesquisas, sendo uma dissertação, de Lucas Prestes, com conclusão prevista para 2018, e uma tese, de Claudia Carnevskis (2018). Esses estudos, ao mesmo tempo que possuem similitudes, também apresentam especificidades de cada região, ampliando as diferenças e considerando novas problemáticas e novos desafios para a pesquisa.

Na primeira parte dos estudos, o levantamento de Hillesheim (2013) considerou as publicações de teses e dissertações brasileiras sobre o tema da formação de professores de Arte nas licenciaturas. Já o estudo de Azevedo (2014) debruçou-se

1 Ministerio de Ciencia, Tecnología y Innovación Productiva - Ver: $<$ https://www.argentina.gob.ar/ciencia $>$.

2 Coordenação de Aperfeiçoamento de Pessoal de Ensino Superior - Ver: <http://www.capes.gov.br>.

3 Udesc, UERJ, UFPR, UEPG, Univasf, Ufam, Ufes, UFMS, UFMA, UFSB, UFRB e UFRR.

4 IFSC, IFPR e Ifes.

SILVA, Maria Cristina da; ALVARENGA, Valéria Metroski de; BELLAN, Claudia Carnevskis.

Observatório da formação de professores de Artes Visuais: uma análise à luz das políticas vigentes. 
sobre a análise das ementas e bibliografias das disciplinas de História da Arte em três universidades brasileiras e duas argentinas, com a intenção de compreender como os conteúdos de América Latina foram inseridos nesses cursos. Os estudos posteriores da equipe da Udesc debruçaram-se sobre a análise curricular das licenciaturas em Artes Visuais de Santa Catarina, Paraná, Rio Grande do Sul e Regiões Nordeste e Norte.

Neste artigo, aborda-se especificamente um comparativo entre os cursos de Artes Visuais das Regiões Norte e Sul.

\section{A formação de professores: desafios postos a partir dos anos de 1990}

Embora a década de 1990 tenha transposto o ciclo de reorganização do capitalismo vivido nos anos de 1980, ela trouxe para a área de educação, por consequência do ensino de Arte, uma ode de reformas que buscavam emparelhar as políticas públicas dos países com os documentos mundiais propostos por organismos internacionais que, aliados a determinados países, buscaram uniformizar a educação daqueles mais pobres (realidade predominante na América Latina). Essas reformas tinham como objetivo maximizar a "eficiência" educacional sob a perspectiva liberal (maior lucro/menor custo). Cabe ressaltar que as reformas desse período criaram uma base para ampliar a lucratividade da educação, constituindo-se um espaço de expansão econômica. O Banco Mundial, a Unesco, entre outros organismos internacionais produziram documentos capazes de orientar as reformas nos países, nesse caso, da América Latina.

Para implementar os pilares do Relatório Delors ${ }^{5}$, o Banco Mundial investiu em "insumos educativos", como aponta Mazzeu (2011). Há textos escolares, capacitação docente, tempo de instrução, avaliação de aprendizagem assessorando os governos para implementar essa política. O quadro a seguir demonstra as práticas de implementação da política neoliberal na educação.

5 Relatório produzido sobre a coordenação de Jacques Delors em 2010 para a Unesco, sintetizando os pilares neoliberais sobre a educação no século XXI. 


\section{Quadro 1 - Práticas de implementação da política neoliberal na educação}

\section{Onde investem esses organismos?}

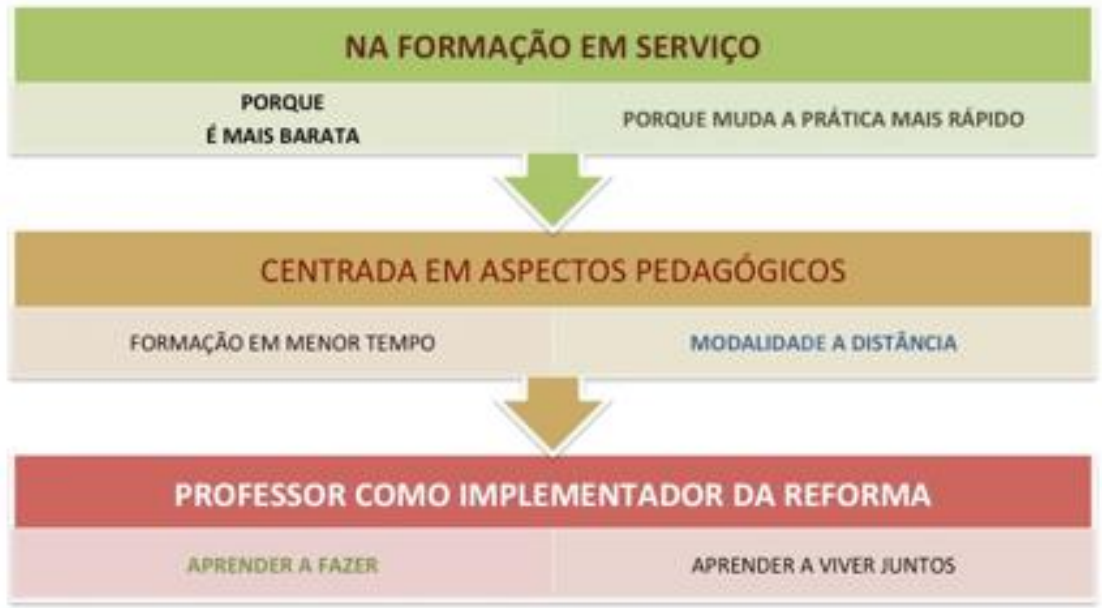

Fonte: autoras, 2018.

O relatório do Banco Mundial destaca a formação por competências e para a pesquisa (com vista à resolução de problemas imediatos), e essas como eixo articulador dos processos formativos, tendo como orientação a reflexão sobre a prática.

Saviani (1996), no sentido de contrapor-se à visão utilitarista da formação, aborda o papel do conhecimento científico para o desenvolvimento do trabalho educativo, considerando sua importância para a compreensão da realidade na qual a prática pedagógica se desenvolve, e seu conteúdo histórico cultural e social, imprescindível ao processo de humanização dos indivíduos.

As reformas e os documentos trazem, implicitamente, a concepção de que o professor necessita aprender de forma aplicada, vinculado com o imediatismo do trabalho, de modo geral, considerado trabalho proletarizado e desumanizado. Esse tema remete às ideias do movimento Escola Nova, como aborda Saviani (2007), retirando o eixo do processo educativo do lógico para o psicológico; dos conteúdos para os métodos; do professor para o aluno; do esforço para o interesse; e da disciplina para a espontaneidade. 
Considera-se, assim, que a aprovação da Nova Base Nacional Comum Curricular (BNCC) tem como objetivo alinhar a escola e a formação a esse modelo de educação utilitária, inclusive, interferindo nas licenciaturas com o objetivo de formar um novo tipo de trabalhador. A formação que, antes, privilegiava conhecimentos e saberes teóricos, desloca-se para uma abordagem dando ênfase ao saber fazer (utilitário e pragmático), que é requerido pelo mercado.

\begin{abstract}
A emergência da noção e do modelo de competências parece vir fortemente associada as novas concepções de trabalho, e traz implícita as mesmas concepções de mundo da indústria e da empresa - fundadas na flexibilidade e na reconversão permanente, que trazem em seu interior, componentes como autonomia, responsabilidade, capacidade de comunicação e polivalência. (NORONHA, 2008, p. 30, grifo do autor).
\end{abstract}

Analisar a categoria trabalho é condição para pensar um processo contrahegemônico, ou seja, é buscar saídas possíveis para o projeto conservador do capital. Segundo a análise de Maués (2013, p. 11), é possível identificar uma tendência crescente;

[...] que se precisa de outra mundialização, de uma globalização diferente daquela que aumentou a miséria, a exclusão, o desemprego, a dívida dos países em desenvolvimento, o número de analfabetos. Cresce o movimento para a criação de uma globalização das lutas sociais, de uma mundialização das resistências, movimentos esses organizados nas diferentes áreas da sociedade, das quais a educação é uma delas.

Tomando como pano de fundo esse cenário, pode-se dizer que a mercantilização da educação chega à formação de professores por meio da aplicação das políticas públicas na formação inicial, na formação continuada por meio de insumos e na valorização de um conjunto de slogans travestidos, na maioria das vezes, com um discurso de mudança, mas que, com uma análise histórica mais profunda, possibilita identificar que as mudanças sugeridas culpabilizam os professores, precarizam suas condições de trabalho e tiram deles a sua ação como intelectual.

Construir uma alternativa para essa realidade passa por análises sistemáticas frente às necessidades de rever as políticas, as práticas de formação e as especialidades das Artes Visuais. 


\section{Análise da problemática das licenciaturas em Artes Visuais da Região Norte}

Para a compreensão do panorama da formação de professores na Região Norte do Brasil, é necessário compreender que, embora detenha grande parte do território brasileiro, as condições sociais, econômicas e políticas dessa região são muito destoantes das encontradas na Região Sul. Em relação às outras regiões, o Norte possui as piores coberturas de saneamento básico e de redes de comunicação, além da menor taxa de atendimento a creches e pré-escolas e a maior relação de distorção idade-série tanto para o ensino fundamental quanto o médio 6 .

A distância entre as cidades é medida por tempo de deslocamento e não por quilômetros. O escoamento da produção regional é precário, caro e, em grande parte, fluvial. Muitas cidades da Região Norte não são acessíveis via terrestre. O impacto desse distanciamento logístico pode ser verificado a partir da análise dos cursos de licenciatura em Artes Visuais (CARNEVSKI, 2018).

O extenso número de comunidades ribeirinhas, de escolas com composição de uma única sala multisseriada, de calendários escolares com composições variadas para o atendimento dos ciclos de chuva, da formação acadêmica incompatível com o desenvolvimento profissional dos docentes, de dificuldades de locomoção dos estudantes (mesmo com a existência do Programa Caminho da Escola, regulamentado e fiscalizado pelo $\mathrm{MEC}$ ), e de escolas de área urbana, há um conjunto de carências que compõe o cenário da educação básica pública na Região Norte Brasileira exigindo mais investimentos.

O processo de expansão, fruto das políticas públicas a partir do governo Lula, permitem a interiorização, bem como a expansão da modalidade a distância.

Quanto ao número absoluto de cursos de licenciatura em Artes Visuais, a Região Norte apresenta oito cursos presenciais públicos e três de instituições privadas e na modalidade de ensino a distância (EAD) são oferecidos três cursos por

6 Segundo dados do MEC/INEP/Diretoria de Estatísticas Educacionais (2017). http://portal.inep.gov.br/estatisticas-educacionais 
universidades públicas e 31 por instituições privadas, de acordo com o Ministério da Educação (e-Mec).

No que se refere à atuação do Observatório da Formação de Professores em Artes Visuais no Norte do país, conforme Carnevski (2018), o foco está direcionado à formação de professores por cursos presenciais oferecidos por universidades públicas, em um estudo que busca compreender como o tema da cultura e das Artes Visuais é abordado, a inclusão desses conteúdos nas disciplinas, e quais os possíveis desdobramentos na ação docente dos futuros formandos, analisando-se ainda a inserção dos cursos de licenciatura em Artes Visuais no Norte do país.

Segundo a autora supracitada, os cursos presenciais se apresentam em quatro capitais (Belém, Manaus, Porto Velho e Boa Vista) e quatro cidades de interior (Arraias e Tocantinópolis - do extremo Norte e Sul de Tocantins, respectivamente -; Parintins - Amazonas -e Marabá - Pará).

Os cursos de EAD estão espalhados por diversas cidades dos estados do Norte, no entanto, a autorização de abertura de polo em uma cidade não constitui em si uma afirmação de curso ativo com estudantes de graduação. Assim, até o momento, não foi possível verificar o impacto desses cursos públicos e privados para a formação de professores de Artes Visuais da Região Norte.

Ainda sobre a EAD, é possível ressaltar que a Universidade Federal do Amazonas (Ufam) e a Universidade de Brasília (UNB) são as representantes nessa modalidade, sendo que as instituições privadas estão, em sua maioria, com polos ativos em todos os estados: Centro Universitário Claretiano (Ceuclar), Universidade Pitágoras (Unopar), Universidade Paulista (Unip), Centro Universitário Internacional (Uninter), Centro Universitário Leonardo da Vinci (Uniasselvi) e Universidade Cidade de São Paulo (Unicid).

A política de terceirização da formação ampliou-se no governo Temer, pois, se antes havia a obrigação de ter o respectivo curso presencial para oferecer a modalidade EAD, a partir do Decreto n. 9.057/2017, deu-se a possibilidade de pedir credenciamento para oferta da EAD sem a experiência de oferta presencial. 
A expansão dos cursos de licenciatura no Norte do Brasil, no que se refere ao ensino público, gratuito e presencial, deu-se via Programa de Apoio a Planos de Reestruturação e Expansão das Universidades Federais (Reuni), aumentando de dois para seis o número de cursos existentes. Outro impacto foi com o Programa de Apoio à Formação Superior em Licenciatura em Educação do Campo (ProCampo), que trouxe os únicos dois cursos representativos, ainda que polivalentes, com a licenciatura em Educação do Campo: Artes e Música.

Os professores formadores nas universidades do Norte do Brasil são, em sua maioria, especialistas ou mestres, e a área de formação em Arte é reduzida. No interior do Amazonas, o colegiado de Artes Visuais tem mais da metade de seu quadro docente formado por professores que possuem apenas a graduação, não sendo raro encontrar professores com essa titulação nos outros colegiados estudados.

A questão da titulação implica principalmente obtenção de recursos via editais públicos, criação de grupos de pesquisa e, diretamente, produção científica de toda a Região Norte do Brasil. Assim, a elaboração de pesquisas científicas é escassa e as pesquisas existentes são desenvolvidas por centros externos ou de outras áreas do conhecimento.

A política existente para capacitação dos profissionais é pautada no afastamento dos professores para o desenvolvimento de mestrados e doutorados, no entanto, o alto número de professores que necessita de capacitação em nível de pósgraduação e de exonerações a pedido de servidores, entre outras justificativas, faz com que a formação docente no nível de doutorado ainda seja uma meta de médio e longo prazos nas instituições públicas.

No que se refere à formação dos docentes das universidades públicas, ganha destaque o grande número dos sem formação (ao menos não acadêmica) em Artes Visuais. A partir dos projetos pedagógicos, é possível verificar um grande número de docentes formados em Letras, História, Música e Teatro. Isso talvez explique a grande quantidade de disciplinas não relacionadas à área e, no caso de Tocantinópolis e Arraias, justifique ainda um redirecionamento da formação oferecida pelos cursos. 
É importante considerar a ausência de levantamento de dados referentes aos professores de Artes Visuais formados (e em formação) em cursos do Plano Nacional de Formação de Professores da Educação Básica (Parfor). Ressalta-se que a matrícula em cursos dessa natureza só é possível para professores já atuantes na rede pública de ensino. Oferecidos de forma modular, os cursos do Parfor são uma oportunidade de formação, geralmente a única possível de conciliar, principalmente para docentes atuantes nas áreas rurais. É necessário que, em outro estudo, seja feita uma análise aprofundada do desempenho do Parfor na formação docente (CARNEVSKI, 2018).

Em contrapartida, os esforços de implantação e permanência dos cursos na região, à revelia de toda a pressão política atual, assinam o compromisso com a inserção de novos professores atuantes no ensino das Artes Visuais. Em uma realidade como a apresentada pelo projeto pedagógico do curso de Artes Visuais da Unifesspa, que destaca os dados obtidos no censo do IBGE de 2010, em que $14 \%$ da população de Marabá nunca havia frequentado creche ou escola e pouco mais de $2 \%$ frequentou o ensino superior, a criação dos cursos de Artes Visuais pode ser considerada, assim como os autores do projeto pedagógico esclarecem, uma conquista histórica.

Outro aspecto importante é a indagação levantada no projeto pedagógico do curso de licenciatura em Artes Visuais da Universidade Federal de Rondônia (UNIR, p. 12) sobre "Como desenvolver uma formação em artes para um futuro educador sem ou com acesso precário à produção contemporânea e às discussões teóricas da área?". A pergunta se firma nas apresentações que se seguem nos demais PPCs, da restrição ao acesso bibliográfico e digital e da ausência de museus e escassez de espaços artísticos, aqui apresentados para a realidade de Rondônia, mas que ilustram a realidade da Região Norte como um todo. Como saída, o curso apresenta, diante do pouco interesse político no patrimônio artístico-cultural material e imaterial, que a universidade seja uma referência na distribuição desses conteúdos, não só nas atividades de ensino, como nas de pesquisa e extensão. 
Carnevskis, Macalini e Silva (2016, p. 132) destacam que a falta de investimentos na Região Norte auxilia no processo de precarização do trabalho docente:

Consideramos que no âmbito educacional há peculiaridades na intervenção das políticas estatais neoliberais. A medida que racionaliza os gastos com a educação e que leva a sua precarização, ao qual fica evidente os benefícios para o mercado da educação e do seu empresariado.

Mesmo com a ampliação e interiorização dos cursos de licenciatura em Artes Visuais, há escassez de recursos para implantação e solidificação deles na Região Norte. No caso do curso da Ufam, implantado em Manaus na década de 1970, e sua expansão em Parintins no ano de 1990, os autores descrevem que esse processo foi permeado por mudanças curriculares nas duas realidades, ora para atender às políticas, ora para atender às necessidades da região.

\section{Análise da problemática das licenciaturas em Artes Visuais da Região Sul}

As Regiões Sul e Sudeste do Brasil apresentam as taxas mais elevadas de escolarização, se comparadas às demais regiões. O Sudeste fica em primeiro lugar. Tais regiões também se distinguem das demais devido à intensa industrialização na Região Sudeste e a uma industrialização mais específica na Região Sul - a agrícola. O acentuado desenvolvimento econômico dessas regiões advém da estruturação da colonização do país (VIEIRA; ALBERT; BAGOLIN, 2008 apud AZEVEDO, 2014). Nesse sentido, a grande quantidade de cursos na Região Sul pode ser justificada tanto pela sua organização econômica, como pela grande densidade demográfica, se comparada à Região Norte.

Os cursos de licenciatura em Artes Visuais são influenciados por vários documentos, o que é fruto das políticas públicas atuais. O primeiro deles são as Diretrizes Curriculares de Artes Visuais que disciplinam a oferta (Resolução n. 1, de 16 de janeiro de 2009), a organização e os conteúdos abordados nos cursos. Igualmente, os cursos de licenciatura são modelados por políticas gerais que atendem à formação para a educação básica como um todo. A Resolução n. 2, de julho de 
20157 , já analisada por Fonseca da Silva e Bujan (2016), é um dos documentos que fundamenta as reformas curriculares das licenciaturas.

A quantidade de cursos de licenciatura em Artes Visuais, tanto presenciais quanto por EAD na Região Sul, em comparação com o restante do Brasil, é grande. De acordo com Alvarenga (2015), que coletou dados do Instituto Nacional de Estudos e Pesquisas Anísio Teixeira (Inep), em 2013 havia 156 cursos dessa área em todo território nacional e a Região Sul concentrava 54 desses cursos, ou seja, praticamente um terço dos cursos de licenciatura em Artes Visuais do Brasil. Esse montante, de acordo com e-Mec, estavam divididos da seguinte forma: 18 cursos de licenciatura em Artes Visuais no Paraná, 22 em Santa Catarina, e 14 no Rio Grande do Sul. Essa diferença na quantidade de cursos ofertados em cada estado modificou-se nos anos subsequentes, visto que muitos cursos foram fechados devido à falta de interesse por eles (baixa procura) nos processos seletivos.

Alvarenga (2015) realizou um levantamento da relação candidato/vaga pelos cursos de licenciatura em Artes Visuais nesses três estados da Região Sul, selecionando cinco Instituições de Ensino Superior (IES) públicas de cada estado, que ofertavam os cursos de licenciatura em Artes Visuais presenciais para verificar a concorrência deles entre os anos de 2004 e 2013. Ela constatou que, dentre os cursos analisados, o Paraná foi o que apresentou a maior relação candidato/vaga.

Pera e Fonseca da Silva (2014, p. 3.784) entrevistaram os coordenadores dos cursos de licenciatura em Artes Visuais em Santa Catarina e um deles afirmou que “[...] nos primeiros anos tínhamos uma entrada de 50 alunos, mas nos últimos 6 a 7 anos a entrada tem sido cada vez mais reduzida, este ano, 2014, tivemos uma entrada de 24 alunos". Ou seja, isso reafirma o que foi constatado na pesquisa sobre a relação candidato/vaga realizada por Alvarenga (2015) na Região Sul.

7 Define as Diretrizes Curriculares Nacionais para a formação inicial em nível superior (cursos de licenciatura, cursos de formação pedagógica para graduados e cursos de segunda licenciatura) e para a formação continuada. 
No Rio Grande do Sul, Müller e Silva-Santos (2016) verificaram que, em 2016, havia nesse estado cinco cursos de licenciatura em Artes Visuais públicos e quatro privados, mas, entre os anos de 2011 e $2013^{8}$, três cursos de licenciatura em Artes Visuais foram fechados.

Alvarenga (2015), ao verificar a titulação dos professores universitários dos cursos de licenciatura em Artes Visuais no Paraná, constatou que muitos ainda não possuíam doutorado e/ou o estavam cursando. Nesse aspecto, ressalta-se a ausência de programas de pós-graduação em Artes Visuais no Paraná.

Quanto à localização dos cursos de licenciatura em Artes Visuais na Região Sul, em Santa Catarina, de acordo com Pera e Fonseca da Silva (2014), havia uma distribuição homogênea de cursos presenciais espalhados pelo estado, excetuandose a Região do Planalto Serrano. Já no Rio Grande do Sul, Silva e Müller (2017) afirmaram que os cursos presenciais de licenciatura em Artes Visuais concentram-se nas Regiões Metropolitana e sul, todos com predominância na faixa litorânea, enquanto o Noroeste e a Região Central do estado não apresentam cursos nessa modalidade. Por fim, no Paraná, Alvarenga (2015) afirma que há uma distribuição geográfica homogênea de cursos presenciais em todo o estado. No entanto, a maior concentração de cursos públicos está na Região Metropolitana, enquanto que na Região Oeste há uma concentração maior de cursos com categoria administrativa privada.

Ainda não foi realizado um mapeamento dos polos dos cursos ofertados na modalidade de EAD no Paraná e Rio Grande do Sul para verificar se tais cursos suprem a carência de algumas localidades específicas nesses estados. Ressalta-se que a proliferação da oferta de EAD flexibiliza ainda mais essa oferta, não sendo mais necessário ter o curso presencial para ofertar-se a modalidade EAD. No entanto essa medida, na análise do observatório, é mais uma estratégia em que o governo brasileiro abre mão do processo de formação e entrega-o para a iniciativa privada, representada pelo modelo de EAD.

8 O e-Mec costuma manter em seu site cursos que estão em processo de fechamento.

\footnotetext{
SILVA, Maria Cristina da; ALVARENGA, Valéria Metroski de; BELLAN, Claudia Carnevskis.

Observatório da formação de professores de Artes Visuais: uma análise à luz das políticas vigentes.

Revista GEARTE, Porto Alegre, v. 5, n. 2, p. 272-288, maio/ago. 2018.

Disponível em: http://seer.ufrgs.br/gearte 
Em Santa Catarina, já existem dados a respeito da EAD. De acordo com Fonseca da Silva (2017, p. 11), há "[...] quatro instituições que oferecem a formação na modalidade de EAD: Uninter, Uniasselvi, Unipe e Unopar. Juntas, essas instituições de ensino superior (IES) possuem 115 polos na modalidade a distância." Esses cursos são ofertados por IES privadas e ampliam a oferta de licenciatura em Artes Visuais nesse estado. O impacto da EAD na formação de professores de Artes Visuais já é visível. O grupo de pesquisa ligado ao observatório na Udesc tem aprofundado o estudo sobre a modalidade $\mathrm{EAD}^{9}$.

Apesar de a concentração dos cursos presenciais de licenciatura em Artes Visuais com categoria administrativa pública ser maior na Região Metropolitana e Litorânea, é preciso ponderar a respeito da densidade demográfica dessas localidades, pois, segundo o censo de 2010 do Estatuto Brasileiro de Geografia e Estatística (IBGE), a maior concentração populacional brasileira está, de fato, nessas regiões. Há estreita relação entre os dois elementos: melhores condições de desenvolvimento econômico e maior densidade demográfica.

A partir desses dados, pode-se inferir que, apesar de a Região Sul apresentar uma grande quantidade de cursos de licenciatura em Artes Visuais, a distribuição deles, a relação candidato/vaga, nos três estados, não é homogênea. Excetuando-se o Paraná, vê-se que vários cursos de Santa Catarina e Rio Grande do Sul foram fechados devido à baixa concorrência. Acredita-se, aqui, que esse fenômeno é influenciado pela ampliação desordenada da modalidade EAD.

O observatório tem reunido esforços para consolidar seus estudos na temática da oferta de cursos de EAD, mas, por questões de recorte, aqui ateve-se somente aos aspectos já abordados neste texto. Esse é um tema que necessita maiores estudos, tanto de sua organização, como também de análise do impacto na formação de professores de Artes Visuais no Brasil.

9 No atual momento estamos coletando dados sobre esse tema: número de professores sem formação, com formação, formados na modalidade presencial e na modalidade EaD. 


\section{Considerações finais}

Mesmo distante geograficamente, Norte e Sul formam professores de Artes Visuais de maneira muito semelhante. De modo geral, a prática social específica é desconsiderada e o tema dos conteúdos historicamente acumulados também é precariamente abordado em uma perspectiva crítica. O modus operandi das licenciaturas assemelha-se a uma linha de montagem fordista, perdendo-se a oportunidade de responder aos problemas específicos da região. A partir dos dados coletados, percebe-se que as IES que ofertam cursos de licenciatura em Artes Visuais na modalidade EAD, em geral, são as mesmas nas duas regiões, o que pode gerar essa homogeneização dos conteúdos, independentemente da localização geográfica.

Outra semelhança que se destaca entre os cursos de licenciatura em Artes Visuais nas Regiões Norte e Sul é que a distribuição deles não é homogênea tanto em relação à quantidade de cursos distribuídos pelos estados pertencentes a cada uma das regiões, quanto em relação à localização deles. Em geral, os cursos presenciais públicos concentram-se nas capitais e/ou na Região Metropolitana, enquanto que os cursos privados, ofertados na modalidade EAD, abrangem os demais locais.

Quanto às diferenças existentes, destacam-se o baixo número de cursos de graduação em Artes Visuais e a pequena quantidade de programas de pós-graduação stricto sensu na Região Norte (somente um no Pará), se comparado com a Região Sul, que apresenta uma oferta mais ampla (UDESC, UFRGS, UFPEL e UFSM). Outra diferença refere-se à titulação da maioria dos professores universitários que, na Região Norte, consiste em especialistas, mestres e/ou de professores que nem possuem doutorado em Artes Visuais, enquanto que na Região Sul a maioria dos que atuam no nível superior possuem mestrado e/ou doutorado. Por fim, outra distinção entre elas consiste na quantidade de museus e/ou espaços culturais.

Todas essas diferenças geram efeitos distintos no que se refere à pesquisa, acesso a recursos públicos e aprimoramento da área. É preciso considerar que essas diferenças não são naturais, mas construídas levando-se em consideração ações políticas, ocupação demográfica distintas, investimentos no desenvolvimento SILVA, Maria Cristina da; ALVARENGA, Valéria Metroski de; BELLAN, Claudia Carnevskis. 285 Observatório da formação de professores de Artes Visuais: uma análise à luz das políticas vigentes. Revista GEARTE, Porto Alegre, v. 5, n. 2, p. 272-288, maio/ago. 2018. 
econômico, social e político diferenciados. Embora a área de Artes Visuais se tenha fortalecido nas diferentes regiões brasileiras nos últimos anos, uma mudança de governo modificou essa realidade.

As políticas públicas internacionais que influenciam a organização, o funcionamento e o financiamento também ganham contornos locais, vinculados ao projeto societário defendido pelos grupos dominantes na realidade brasileira. Alguns projetos que ampliam e interiorizam a formação docente nas licenciaturas, fruto de políticas públicas como o Reuni, necessitam fazer investimentos na mesma dimensão, caso contrário, a formação desqualificada ou aligeirada amplia-se fortalecendo algumas regiões em detrimento de outras.

O projeto do Observatório vem ao longo dos últimos anos analisando dados, números e documentos oficiais, pois é preciso ter um olhar mais detalhado sobre cada um dos aspectos, considerando a materialidade das relações sociais no campo da Educação e da Arte. Por outro lado, analisando-se os dados separadamente, pode-se perder a visão de totalidade, por isso é necessário olhar também o projeto societário na tentativa de reconhecer determinados contextos e preparar educadores para que intervenham na realidade social.

\section{Referências}

ALVARENGA, Valéria Metroski de. Formação inicial do professor de artes visuais: reflexões sobre os cursos de licenciatura no Estado do Paraná. 2015. 256f. Dissertação (Mestrado em Artes Visuais) - Udesc, Florianópolis, 2015.

AZEVEDO, Isadora Gonçalves de. O lugar da América Latina na formação inicial de professores de Artes Visuais no Brasil e na Argentina. Dissertação (Mestrado em Artes Visuais) - Udesc, Centro de Artes, 2014.

BRASIL. IBGE. Censo 2010. Disponível em: <https://censo2010.ibge.gov.br/noticiascenso.html?view=noticia\&id=1\&idnoticia=2501\&busca $=1 \&$ t=ibge-lanca-mapa-densidade-demografica2010>. Acesso em: 29 out. 2017.

BRASIL. MEC. Resolução $n$. 1, de 16 de janeiro de 2009. Disponível em: <http://portal.mec.gov.br/cne/arquivos/pdf/2009/rces001_09.pdf>. Acesso em: 28 out. 2017.

BRASIL. MEC. Resolução n. 2, de 01 de julho de 2015. Disponível em: <http://portal.mec.gov.br/secretariade-regulacao-e-supervisao-da-educacao-superior-seres/323-secretarias-112877938/orgaos-vinculados82187207/21028-resolucoes-do-conselho-pleno-2015> Acesso em: 29 out. 2017.

CARNEVSKIS, Claudia. Formação de professores de artes visuais nas universidades públicas da Região Norte: cultura e arte no currículo das licenciaturas. 2018. Tese (Doutorado em Artes Visuais) - Universidade do Estado de Santa Catarina, Florianópolis.

CARNEVSKIS, Claudia.; MACALINI, Edson e SILVA, E. G. A precarização do trabalho docente nas licenciaturas dos campi em expansão da Universidade Federal do Amazonas. In: SILVA, M. C. R. F;

SILVA, Maria Cristina da; ALVARENGA, Valéria Metroski de; BELLAN, Claudia Carnevskis. 286

Observatório da formação de professores de Artes Visuais: uma análise à luz das políticas vigentes.

Revista GEARTE, Porto Alegre, v. 5, n. 2, p. 272-288, maio/ago. 2018.

Disponível em: http://seer.ufrgs.br/gearte 
SANTOS, V. M. M. (Org.). Formação docente e políticas públicas: cenários e desafios. Florianópolis: Letras Contemporâneas, v. 500, p. 121-136, 2016.

COLLAÇO, Maria Eduarda; JENSEN, Joviana; FONSECA DA SILVA, M. C. R. Recortes de pesquisa a partir do Observatório da formação de professores no âmbito das Artes Visuais. 26은 Seminário de Iniciação Científica da Universidade do Estado de Santa Catarina. Anais... 2016. Disponível em: <http://www1.udesc.br/arquivos/id_submenu/2553/51.pdf>. Acesso em: 28 out. 2017.

FONSECA DA SILVA, Maria Cristina R. Panorama brasileiro das licenciaturas em Artes Visuais: dados a partir do Observatório da formação de professores de Artes. In: CONGRESSO NACIONAL DA FEDERAÇÃO DE ARTE/EDUCADORES DO BRASIL, 27; CONGRESSO INTERNACIONAL DOS ARTE/EDUCADORES, 5; SEMINÁRIO DE CULTURA E EDUCAÇÃO DE MATO GROSSO DO SUL, $2 .$. Anais..., Campo Grande, 2017.

FONSECA DA SILVA, Maria Cristina R.; AZEVEDO, Isadora Gonçalves de; PERA, Luana Pavesi; ALVARENGA, Valéria Metroski de. Análises sobre licenciaturas em Artes Visuais: situação no Brasil e no estado de Santa Catarina. In:ENCONTRO DO GRUPO DE PESQUISA EDUCAÇÃO, ARTE E INCLUSÃO, 10. Anais... Florianópolis, 2014. Disponível em: <https://virtual.udesc.br/eventos/xencontro/04.pdf>. Acesso em: 28 out. 2017.

FONSECA DA SILVA, Maria Cristina R.; BUJÁN, Federico. Políticas públicas de formação docente em artes: perspectivas em duas realidades, Brasil e Argentina. Revista Gearte, v. 3, p. 26-52, 2016.

FONSECA DA SILVA, Maria Cristina R.; SOSNOWSKI, Katyuscia; MAZURKIEVICZ, Gilmar Reflections on Distance education in arts in Brazil: diversity and inclusion. Revista Científica Ciência em Curso. Tubarão: Unisul, 2013.

FONSECA DA SILVA, Maria Cristina R.; HILLESHEIM, Giovana Bianca Darolt; MAKOVIECKY, Sandra. Ensino de arte: um olhar para os espelhos retrovisores. Revista ARS, São Paulo, 2013.

HILLESHEIM, Giovana Bianca Darolt.Um olhar para as pesquisas que abordam a formação de professores de artes visuais: caminhos percorridos e a percorrer. Dissertação (Mestrado em Artes Visuais) -Centro de Artes, Udesc, Florianópolis, 2013.

MAUÉS, Olgaíses Cabral. Reformas internacionais da educação e formação de professores. Cadernos de pesquisa, n. 118, São Paulo, 2013.

MAZZEU, Lidiane Teixeira Brasil. A política educacional e a formação de professores. In: MARSIGLIA, Ana Carolina Galvão (Org.). Pedagogia histórico-crítica: 30 anos. Campinas, SP: Autores Associados, 2011. (Coleção Memórias da Educação).

MÜLLER, Maristela. A pesquisa na formação de professores: uma análise curricular das licenciaturas em Artes Visuais no Rio Grande do Sul. Dissertação (Mestrado em Artes Visuais) - PPGAV Udesc, Florianópolis, 2017.

NORONHA, Olinda Maria. Globalização, mundialização e educação. In: LUCENA, Carlos. (Org.) Capitalismo, Estado e Educação. São Paulo: Alínea, 2008.

PERA, Luana Pavesi; FONSECA DA SILVA, Maria Cristina R. Formação docente em Artes Visuais: análises sobre os cursos de Santa Catarina. In: ENCONTRO NACIONAL DA ASSOCIAÇÃO NACIONAL DE PESQUISADORES EM ARTES PLÁSTICAS, 23. Anais... Belo Horizonte, 2014.

SCHLICHTA, Consuelo Alcioni Borba Duarte; ALVARENGA, Valéria Metroski de. O currículo das licenciaturas em artes visuais no Paraná: as interferências do proposto na lei para a formação e atuação do professor. Revista Palíndromo, n. 14, Florianópolis, 2015.

SANTOS-SILVA, Clarissa; MULLER, Maristela. Mapas de ausências: um olhar sobre as licenciaturas em Artes Visuais no Rio Grande do Sul e no Nordeste. In: ENCONTRO NACIONAL DE PESQUISADORES EM ARTES PLÁSTICAS, 25. Anais... Porto Alegre, 2016.

SAVIANI, Dermeval. Educação: do senso comum à consciência filosófica. 12. ed. Campinas: Autores Associados, 1996.

SAVIANI, Dermeval. História das ideias pedagógicas no Brasil. Campinas: Autores Associados, 2007.

SILVA, Maria Cristina da; ALVARENGA, Valéria Metroski de; BELLAN, Claudia Carnevskis.

Observatório da formação de professores de Artes Visuais: uma análise à luz das políticas vigentes.

Revista GEARTE, Porto Alegre, v. 5, n. 2, p. 272-288, maio/ago. 2018.

Disponível em: http://seer.ufrgs.br/gearte 


\section{Maria Cristina da Rosa Fonseca da Silva}

Possui graduação em Educação Artística pela Universidade do Estado de Santa Catarina (1988), mestrado em Educação pela Universidade Federal de Santa Catarina (1998) e doutorado em Engenharia de Produção pela Universidade Federal de Santa Catarina (2004) na linha de mídia e conhecimento. Em 2010 realizou Estágio de Pós-doutorado na Universidad de Sevilla/Espanha desenvolvendo pesquisa junto a Escola da Organización Nacional de Ciegos Espanõles. É professora titular do Centro de Artes da Universidade do Estado de Santa Catarina. Atua como professora do Mestrado e doutorado em Artes Visuais da UDESC. Linha de investigação Ensino de Arte. Tem experiência na área de Educação, com ênfase em Educação Inclusiva, atuando principalmente nos seguintes temas: formação de professores, ensino de artes, educação inclusiva e a distância. É Coordenadora do Laboratório Interdisciplinar de Formação de Educadores - LIFE da UDESC.

E-mail: cristinaudesc@gmail.com

Currículo: http://lattes.cnpq.br/5794119392714925

\section{Valéria Metroski de Alvarenga}

Doutoranda e Mestre em Artes Visuais (UDESC). Graduada em Artes Visuais (Licenciatura e Bacharelado/UFPR). Atualmente leciona a disciplina de Arte na Secretaria do Estado da Educação (SEED/PR). Membro do Grupo de Pesquisa "Educação, Arte e Inclusão" e do projeto de pesquisa "Observatório da Formação de Professores no âmbito do Ensino de Arte: estudos comparados entre Brasil e Argentina" (UDESC). Tem experiência com o Ensino Fundamental II, Ensino Médio, Educação de Jovens e Adultos (EJA) e Licenciatura em Artes Visuais na modalidade EaD. Tem interesse nas seguintes áreas/temas de pesquisa: formação do(a) professor(a) de arte, ensino de arte, políticas educacionais e currículo.

E-mail: valeriametroski@hotmail.com

Currículo: http://lattes.cnpq.br/2380674209566505

\section{Claudia Carnevskis Bellan}

Graduada em Educação Artística pela Universidade Estadual Paulista (2005), mestre em Educação pela Universidade Federal de São Carlos (2010) e doutora em Artes Visuais pela Universidade do Estado de Santa Catarina (2018). Atualmente é professora assistente do Colegiado de Licenciatura em Artes Visuais da Universidade Federal do Amazonas- Campus Parintins. Tem experiência na área de Educação,atuando principalmente nos seguintes temas: cultura, arte, movimentos sociais, educação e arte-educação e formação de professores de artes.

E-mail: claudiadeartes@gmail.com

Currículo: http://lattes.cnpq.br/8738747125393663

Recebido em 30 de maio de 2018 Aceito em 19 de julho de 2018 